\title{
Reading videogames as (authorless) literature
}

\section{Richard Berger and Julian McDougall}

\begin{abstract}
This article presents the outcomes of research, funded by the Arts and Humanities Research Council in England and informed by work in the fields of new literacy research, gaming studies and the socio-cultural framing of education, for which the videogame L. A. Noire was studied within the orthodox framing of the English literature curriculum at A level (pre-university) and undergraduate (degree level) in the United Kingdom. A mixed methods approach was adopted. Firstly, students contributed to a gameplay blog requiring them to discuss their in-game experience through the 'language game' of English literature, culminating in answering a question constructed with the idioms of the subject's set text 'final examination'. Secondly, students taught their teachers to play L. A. Noire, with free choice over the context for this collaboration. Thirdly, participants returned to traditional roles to work through a set of study materials, designed to reproduce the conventions of the 'study guide' for literature education. Fourthly, interviews were conducted after each phase. The interviews informed a redrafting of the study materials, which are now available online for teachers. In the act of inserting the study of L. A. Noire into the English literature curriculum as currently framed, this research raises epistemological questions about 'subject identity', and the implications for digital transformations of texts for ideas about cultural value in schooled literacy and also the politics of 'expertise' in pedagogic relations.
\end{abstract}

Key words: literacy, videogames, English literature, digital transformations, pedagogy

\section{Research context}

There is a plethora of published research into the kinds of literacy practices evident in videogame play, virtual world engagement and related forms of digital reading and writing (Apperley and Walsh, 2012; Bazalgette and Buckingham, 2012; Gee, 2003; Juul, 2005; Merchan et al., ) as well as the implications of such for home/school learning (Dowdall, 2006; Jenkins, 2006; Potter, 2012) and for teachers' own digital lives (Graham, 2008). Such studies have tended to focus on younger children and this research is also distinct from such work in the field in its exploration of the potential for certain kinds of videogames to be understood as 'digital transformations' of conventional 'schooled' literature. The outcomes of this project raise implications of such a conception for further implementation of a 'reframed' literacy (Marsh, 2007) within the contemporary curriculum of a traditional and conservative 'subject'.

L. A. Noire was released in May 2011 (Rockstar Games, 2011). The diegesis is set in 1947, and the game appropriates conventions from American film noir texts of the 1940s and 1950s, as well as later texts such as Alphaville (Godard, 1965) and L. A. Confidential (Hanson, 1997). The 'hard-boiled' detective fiction of Elmore Leonard and James Ellroy also contributes to this 'sphere of influence'. Unlike these novels and films, of course, L. A. Noire is an author/auteur-less digital event, which is pre-designed but 'written', in narrative terms, only when read (played). The intention to 'digitally transform' the hard-boiled detective novel might call us to further examine the relationship of exchange that exists between linear and digital texts - an 'in between' space - and how this is framed in and by social literacy practices. Equally significant is the subsequent exploration of how gamer students and English teachers might work with $L$. A. Noire to reconfigure dynamics of expertise and, potentially, begin a remediation of the curriculum. These shifts would begin a (digital) transformation of what we think it means to 'read' about the function of texts and the nature of textual 'authority' in the digital age.

\section{Reading games}

This research inquiry is concerned with teachers' and students' understandings and assumptions about text and literature within a curriculum discourse, seeking a direct intervention in the pursuit of theorising discourses of authorship (AHRC, 2011; Colvert, 2012; Kress, 2010) through 'schooled' engagement with an 'authorless' text.

The analysis of Collins (2010) of how 'book culture' has adapted to survive through integration into visual media does not extend beyond the shifting context for a preserved definition of reading - of literature (also a preserved category, set apart from popular fiction) in the form of words on pages or screens or filmic adaptations of those words: 
"If literacy ultimately depends on a set of assumptions about what is worth knowing, what does popular literary culture promise to deliver, since it provides not just the books for everybody, but the reasons for having a literary experience for everybody, in whatever format it may be encountered?" (Collins, 2010, p. 18)

Collins makes no mention of videogames in this account of the reframing of literature. Nor does he challenge this 'set of assumptions' about the epistemology of literacy. The tension at the heart of our study is that the selection of a 'literary' game sets up a similarly 'partial' intervention. Integrating $L$. A. Noire into English literature study also merely accounts for the 'popularisation and relocation' of cultural reproduction.

Potter (2012) builds on the tradition of new literacy studies - whereby research into social literacy practices must account for their configurations within both 'local' settings and broader structuring and regulating conditions (Street, in Grenfell et al., 2012) - and its divergence in 'multimodality' and 'transmedia' to develop a theory of 'curatorship' as a metaphor for understanding engagement with new digital media as an extension of and negotiation of the self (Davies, 2009). Of key interest for our research is Potter's suggestion that we view the home/school boundary as follows:

"not a solid barrier as such but a semi-permeable membrane through which things of value travel along with the learners themselves" (Potter, 2012, p. 7).

How, then, might a 'reframing' of what counts as literature adapt to include such a fluid flow of textual value? How might the 'utterance' of literature be ignited by a narrative-based videogame, such as $L$. A. Noire? Bakhtin (1994) argues that the initial utterance always anticipates an active response and shapes itself accordingly:

\begin{abstract}
"In the novel, dialogism energises within the very mode in which the discourse conceives of its object and its means of expressing it, transforming the semantics and the syntactical structure of the discourse. Here the dialogical reciprocal orientation becomes, so to speak, an event of discourse itself, animating it and dramatizing it from within in all of its aspects" (cited in Todorov, 1984, p. 60).
\end{abstract}

For Holquist, this dialogism is:

"[A] way of looking at things which always insists on the presence of the other, on the inescapable necessity of outsidedness and unfinalizability" (Holquist, 2002, p. 195).

So, how far should we view L. A. Noire as a digital transformation of, and as such a response to, or in dialogue with the conventional form of the novel?
Videogame play is an awkward and exclusive category for the conceptual 'vertical discourse' (Bernstein, 1996) of literacy. Gamers develop a 'knowing' metaawareness of how to play against, with or despite game narrative, a playful, enacted and embodied criticality (Kendall and McDougall, 2009) that resonates with the (postmodern) 'pick and mix' reader of texts - dialogic reading practices that offer possibilities for 'being' that are difficult to pin down as 'reception'. Such 'parology' (Lyotard and Thebaud, 1985) - new moves in the game that disrupt orthodox analyses of 'effects' and of reading itself - provide compelling evidence that there is no singular 'way of being' in a game event. This has obvious implications for the 'key concept' of the reader in literacy education and for the broader project of bridging new literacy studies and 'practical engagements' in the redistribution of cultural and symbolic forms of capital (Bourdieu, 1986; Grenfell et al., 2012).

Genre is something of a 'precept' for text-conscious disciplines (Bennett et al., 2011, p. 45). While noir is 'seen' as a filmic genre - and this perception is certainly supported by our research - the genre (or style) does have a literary 'heritage'. At the same time, L. A. Noire does not possess the 'author function' (Foucault, 1991), which dominates the literacy practices inscribed by 'subject English' within its figured world of lineage:

"To be able to use a novel properly you should know where the form is coming from historically" (Sutherland, 2007, p. 45).

\section{Focus and methods}

"In other story-telling methods, we see what the characters do - in videogames, we control what they do, within certain boundaries - student participant" (interview).

Working with four groups of teachers (one from each institution) and students (10 from each institution) in A2 (second year of the A level entry qualification to a university in the United Kingdom) and undergraduate (degree) contexts across three geographical locations in England, all participants first contributed to a gameplay blog requiring them to wear both 'hats' of literature student and gamer and to reflect on these overlapping fields and associated habitus (Bourdieu, 1986). Secondly, students from each group whose blog contributions indicated different types of responses to the questions were invited to participate further and to 'train' their teachers to play the game (developing further a strategy for 'inexpert pedagogy' see Andrews and McDougall, 2012; Kendall and McDougall, 2012). Next, these smaller groups worked together on a series of study resources and activities (Figure 1) locating the game as a literary text within the analytical 'lens' of English. Finally, selected participants were interviewed and the resources modified accordingly. 


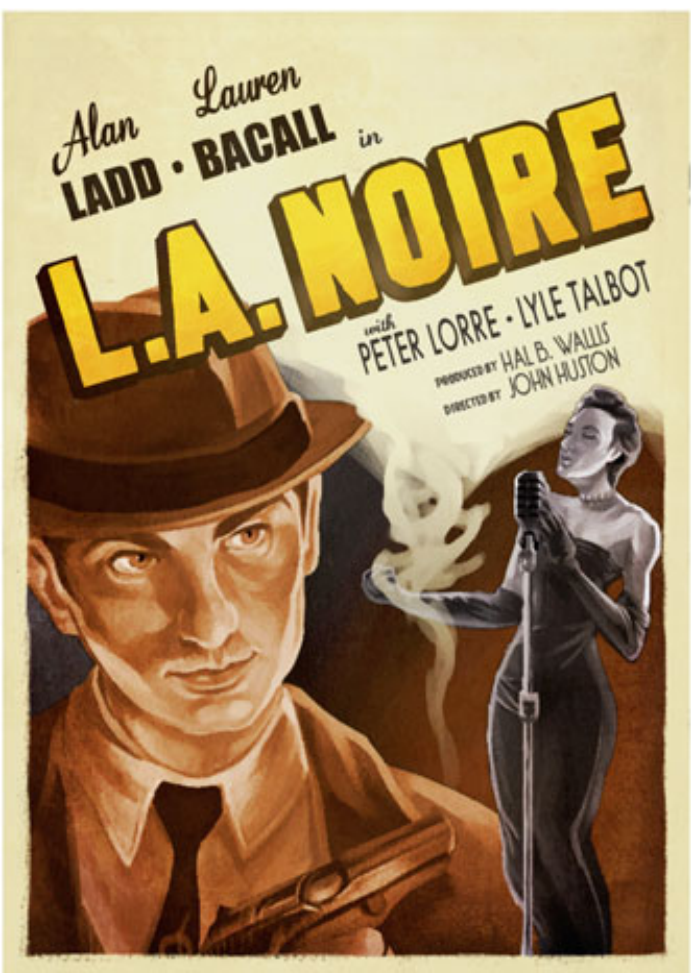

Figure 1: Extended textual fields

"Often, and this has been central to English teaching, the category (literature) includes only what 'adult' experts believe that young adults should read. The 'literariness' of the texts deemed appropriate in this category, often taken for granted within particular regimes of value, needs to be a matter for explicit debate rather than assumed to be a legitimate criteria of inclusion" (Richards, 2011, p. 18).

Our focus, then, is not on the success or failure of inserting L. A. Noire into the English literature curriculum on its current terms, but rather our intervention sets up this kind of 'explicit debate' about what 'counts' as worthy of study and subsequently what can be 'legitimate' literacy (Kendall, 2008), for and in 'subject English', in the context of digital transformations of reading.

\section{Findings}

To map our findings to our key research questions, we begin with three examples by way of introducing the central themes and how our research interventions yielded data in relation to each.

The player/reader embodies Cole Phelps, performing as a detective, investigating and making judgements about corruption. As we can discern from this student/ gamer/blogger, the status of the reader/audience is immediately complex:

"Sticking to the standard that is set by a game which carries film noir characteristics, the main protagonist is a flawed justice seeking detective. The interesting twist however is that we, the players, watch his rise, fall and eventual redemption... Phelps is an interesting character to play, especially as through the facial mapping technology we play as a digitised actor rather than an avatar" (student blog post).

It is clear that the identification with Cole Phelps is problematic on a number of fronts. Some of the participants clearly recognise the boundaries between what Goffman (1990) calls the 'front' and 'back region':

"Much the same in novels, I begin to feel the character, how they interact to [sic] everything" (student blog post).

"My game identity is part me, part Cole" (student blog post).

Although for others it is far more complex; there is resistance on the part of the students in identifying completely with Phelps:

"I found it very difficult to inhabit the character of Cole Phelps; his fate felt predestinated from the outset" (student blog post).

"[Phelps'] backstory and character are so thoroughly constructed that it leaves little room for self-identification" (student blog post).

Clearly however, identification with a character is important:

"I found that whilst playing as Cole Phelps, the flawed hero, I found that I came to dislike him a little" (student blog post).

There clearly was a sense of detachment on the part of the participants in dealing with the less savoury elements of the plot: Phelps' infidelity was an issue for some, whereas others were provoked into questioning the morality of the narrative:

"The crime where the 15 year old aspiring actress is raped and almost murdered. I found it pretty difficult to see the criminals not get arrested" (student blog post).

Turning to the status of the game as an authorless novel and what this means for the teaching of literature, here a teacher articulates a similar 'inexpertise':

"I suppose in terms of looking at it as a text or otherwise looking at it as what you might call different types of text reader relations and I compare that to say 'a book' and does the author control the meaning of the book, audience reaction and it's not too dissimilar in terms of interrogating who controls the game and arguably on the surface at least it's the gamer that controls the game but then you're in a fictional world of which are set by somebody else so I don't know if it's that dissimilar to looking at any other texts" (teacher interview). 
Going further to tease out more 'practical' questions of degrees of 'expertise' required to teach a text, and what this means, here we witness a student working through the implications of being taught by a 'non-reader' - the 'ignorant schoolmaster' (from Rancière, 2009):

\begin{abstract}
"To cover everything and find all the un-lockable stuff you could be spending hours and hours on it so it is different in that sense because I know that you can read into a novel and if you read it front to back you can teach about it but with the game you can play it but to unlock everything to think you're going to be teaching about it I think that would take a lot longer" (student interview).
\end{abstract}

Quite quickly in the project, the participants started to 'curate' (Andrews and McDougall, 2012; Potter, 2012) an assemblage of series of influences across different media. The students drew from other literary texts they had been studying, to draw interesting comparisons with $L$. A. Noire and its cast of characters. One student is reminded of Ian Rankin's novel, Bleeding Hearts, Cole Phelps is directly compared with Arthur Kipps in Susan Hill's The Woman in Black and Dr Fontain in Pat Barker's Regeneration trilogy.

The teachers, however, tended to make reference to more 'classic' film texts, such as the character of Sam Spade in the Maltese Falcon and comparing L. A. Noire's Roy Earle with Hank Quinlan in A Touch of Evil (Welles, 1958).

In the final week on the blog, the participants were set two subject English-style examination questions:

1. Film noir's portrayal of the 'femme fatale' supports the existing social order by building up a powerful, independent woman, only to punish her. To what extent do you agree with this in relation to the portrayal of women in L. A. Noire?

2. L. A. Noire is set in the 1940s Los Angeles. To what extent do you feel that this game would provide an effective introduction to the concept of 'genre'? What are the key characteristics of 'noir'? In your answer you should consider form, structure and language, as well as subject matter.

With most choosing the former, no obvious consensus was formed. All agreed that L. A. Noire portrayed men in positions of power:

"[W]e only see the women through the male characters' eyes." "QQ]uite simply, men dominate the plot of L. A. Noire." "The females shown in L. A. Noire lack power." "Elsa Lightmann fits the stereotype of the femme fatale quite easily"(student blog posts).

There was more disagreement over whether women in the game conformed to typical femme fatale tropes. Responding to the second examination-style question, the few who chose this seemed to agree that $L$. A. Noire was more of a 'neo' noir than taking its cue from the more 'classic' texts associated with it. The reasons for this included the 'modern' protagonist in Cole Phelps, and the overt references to the film, L. A. Confidential, which was cited frequently throughout the project as a likely prime source.

During this final phase, links were increasingly made with literature as the participants looked to other sources to explain the ways in which women and different ethnicities were represented in the game:

"I think [representation] is possibly one of the biggest issues to draw on when analysing any work of literature (be it film, game or text)" (student blog post).

So, it is clear then that some students do not see marked boundaries between novels and games (with cinema often acting as a mediator between the two). The second question particularly focused the students on the genre (or style) of noir, and by doing so, explicitly demonstrated how the 'utterance' of noir can be contained by literature, cinema and games, simultaneously.

"Novels and games are very ... similar in the way they portray both characters and setting" (student blog post).

\section{Curriculum}

The blog posts were used as the basis for the L. A. Noire Study Guide, which purposely foregrounded adaptation and appropriation in developing a methodological toolkit with which to analyse the text. Long the preserve of subject English and Film Studies, adaptation is a means to analyse texts and influences in a completely non-medium-specific way, with no one version of a text taking precedent over another (Berger, 2012). The gap between teachers and students is exposed here as one teacher comments in the interviews that L. A. Noire could not be considered a 'literary' text, "because it is so full of filmic references".

A starting point for this research, however, is the premise that cinema contains the utterance of literature, in much the same way as the modern novel now clearly contains the utterance of cinema. Therefore, L. A. Noire must frame both these utterances, and in time, both literature and cinema will frame the utterance of the videogame. Such a framework exposes the problems inherent in a value-judgement-loaded medium-specific English literature curriculum (our aforementioned subject English) and delimits the scope for studying how the properties of one medium (the novel) can be expressed in another (film and videogames) and vice versa. The same teacher also expressed that any 'novelization' of L. A. Noire would be 'atrocious' and that, "It is rare a novel is a good film". At certain points in the study guide, the students are provoked with the sorts of questions that tackle medium specificity and the 'literacy' of $L$. A. Noire directly and are set tasks that aim to elicit thinking about the game's 'sphere of influence'. Whereas some of the teachers clearly see a 
hierarchy across media, all of the students have no problem in 'flattening' this taxonomy in their approaches to L. A. Noire as a text/event.

\section{Discourse}

The interviews with teachers and students and student responses to our study 'tasks' lead us to identify three emerging discourses spoken by our participants. Our methods of analysis are derived from the work of Fairclough (1995) and Gee (2004)/Gee and Hayes (2011).

The formal educational reading of literature can be understood as a 'figured world' of 'advanced' literacy. Figured worlds are identified by Gee but attributed to Holland and Quinn (1998), as "socially and culturally constructed realms of interpretation" (1998, p. 52) which have a 'simplifying' and limiting effect on agents. Our interest here lies in the potential for the 'use' - in 'subject English' of L. A. Noire to create a 'third space' (Gutierez, 2008, p. 152) where two figured worlds might collide in interesting new ways - that of 'advanced literacy' as legitimated by the curriculum and that of gameplay:

"When we consider our students, their experience is always represented in discourse. They may also encounter different 'figured worlds' through their out of school activities including virtual worlds, play worlds, the worlds of popular culture and fantasy" (Pahl and Roswell, 2005, p. 110).

Fairclough's method of critical discourse analysis (1995) views discourse as triangular - it combines the spoken or written language text (or in this case the material form of the game and its realisation in play, within an intertextual system of written and filmic texts), interaction between people to interpret the text (the channelling effect here of attesting certain areas for discussion within the idioms of English literature - genre, narrative, point of view and gender - themes that are 'significant', with no discussion of who chose these things to call 'themes' in the first place and for what purpose) and social practice (the combined effect of our intervention and the existing social relations of pedagogy and expert/apprentice reader identities). This encounter, we argue, at the same time offers a new form of 'access' to studying literature through the legitimation of gameplay as reading that 'counts' whilst reinforcing the symbolic power structures' work in textual pedagogy.

More broadly, Bourdieu's distinction (1986) between 'habitus' and 'field' is helpful in more precisely exploring how engagements with reading in text-conscious disciplines might only be transformed within rigid demarcations of value, realised in pedagogic practice. In this case, the habitus will describe the appropriation of 'rules' for what counts as legitimate literacy (more or less unconsciously reproduced by students), whilst the field can describe the extended regulatory 'reach' of the classroom - in physical or virtual space.

\section{Discourse: figured worlds}

"Clearly, we do 'read' the text of the game in the sense that we have to de-code it through reference to what we already know of games like this one - but not in exactly the same way that we 'read' a novel or film... Yes we can read the game as well as reading a film or book, but not 'in the same way' in each case" (teacher interview)

"If we go about defining the novel in a conventional way where the reader reads the action but has no ability to dictate the terms of the next steps of where it progresses to and what happens to the protagonist or the antagonist and what happens with resolution to the narrative overall, so they are a literally a spectator, I suppose in a sense Sand Box games in general, of which L. A. Noire is a pretty fine example, do offer the potential to offer a true transformation - if transformation is to be defined as to take the novel as a literary form and expand and change $i t^{\prime \prime}$ (teacher interview).

In the first of these two statements, the habitus is opened up to transformation but ultimately kept intact. On the one hand, this English teacher is comfortable with the notion that reading a game is a legitimate literacy practice. On the other, it is important, in this account, to recognise as 'natural' the insulation between these different 'techniques' for reading - an acceptance of such 'rules' appears to reinforce regulatory aspects of the figured world of 'schooled' literacy. In the second response, the teacher is more open to an equivalence between reading novels and reading games, but this is predicated on a reductive notion of what reading literature amounts to - 'literally a spectator'. As the second teacher is a keen gamer and the first was encountering videogames for the first time as a 'reader', we can observe here a rich phenomenology of figured worlds - each teacher encountering the transformation from a different vantage point. Again, we are drawn back to the respective obligations of Selwyn and Potters (2012) for us to bear witness to the complexity and non-linearity of these transformations, framed as they are by long-standing, but semi-permeable experiences in textual worlds.

\section{Discourse: expertise}

Teacher: "The way we did it was because we all had X-Box Live Gold accounts we were able to work at a distance because, first of all there wasn't many rooms available and we would have had to bring in an $X-B o x$ which would have been too complicated so we decided to do it all online mostly by meeting up in an evening time for an X-Box Live party chat and I don't know how you felt about that but I think it seemed to go okay, how about you guys?"

Student: "It certainly seemed to work and luckily it was mainly looking at a more theoretical talking point 
rather than anything else and for example the Tube Map activity - it was a lot more difficult to do the discussion on that when we were doing it through email, whereas where we were talking before it would be so much easier to do that sort of thing as an interactive whiteboard talk experience."

Teacher: "It would have been better for us to have been in a room really and we suggested if we were going to do this as a bigger task that if someone has an interactive whiteboard and a class full of kids then do it live but also doing it as a spider diagram we said and we suggested that because we needed to be together to do it and my feeling was trying to do this underground map for me created a bit of a barrier because I couldn't really envisage it that way - I thought it would be better as a spider diagram."

Student: "Yeah, this is more of an Art exercise more than anything."

In the above exchange our 'inexpert pedagogy' appears to be articulated. Both the teacher and the students are entirely comfortable with a collaborative approach to the creative task, with the discussion over space and time arising from logistics for group work rather than any orthodox notions of expert knowledge. On this evidence, it appears that reading the game together and responding to it within the curriculum as 'expert' is not controversial, but the practicalities of the online learning and teaching context are open to further discussion. In the following response, another teacher brings these two issues together:

\begin{abstract}
"I suppose in terms of looking at it as a text or otherwise looking at it as what you might call different types of text reader relations and I compare that to say 'a book' and does the author control the meaning of the book, audience reaction and it's not too dissimilar in terms of interrogating who controls the game and arguably on the surface at least it's the gamer that controls the game but then you're in a fictional world which is set by somebody else so I don't know if it's that dissimilar to looking at any other texts. But if you wanted to say 'here is L. A. Noire, the character here is Cole Phelps so let's understand Cole Phelps', well you'd need a lot of gameplay to stand up in front of a group of people and say 'Cole Phelps is this kind of person'" (teacher interview).
\end{abstract}

This is another example of a partial re-framing, in this case of the extent to which 'expert literacy' can adapt for gameplay. The teacher, again, has no problem with the question of $L$. A. Noire as a literary text for study but reinforces the assumption that 'mastery' of the text is a prerequisite for teaching - a very different response to the previous discussion whereby students and teachers appear to be constructing a shared kind of reader reception. In these discussions, the distinction between the process and value of voice, in the terms of Couldry (2010), is at stake. Perhaps the authorless nature of 'game-lit' (to extend Collins' phrasing) would ultimately require, for integration into the literacy curriculum, a kind of 'teacher-less' pedagogy?

\section{Discourse: intertextual literacy}

"In terms of viewing L. A. Noire as a digital transformation of the novel, I think it's definitely possible to view it that way - though it may be more closely related to 'film noir' in its form and genre conventions, the eloquence of the game's script, exemplified in particular by the speech between Cole and his partners while driving around Los Angeles is something which I find is usually reserved for the novel and certainly there are even blatant intertexts in the game in the form of Shelley's poetry that plays a key role in Cole's time on the homicide desk" (student interview).

"There's a contradiction in the question - if it's a game it can't be English Literature. My criticisms of the game would be from a literary perspective. I think there are two weaknesses as a literary text - the limitations on character interaction as he [student] taught me, you can read a character is lying from their facial gestures, that's Harry Potter-esque isn't it, where she drops in those big adverbs? There's a number of adverbs around the way Snape moves that tell you he's bad and I think L. A. Noire is in that country with the exaggerated facial gestures. Secondly, just having looked at the opening to Things Fall Apart and what we were trying to discuss is what Achebe's trying to put across, you know in post-colonial literature, so what the writer is trying to communicate is very important in literature, you're not just searching for one meaning, but trying to uncover what the novel might be about. In the game, you have a much more active participation as a reader you can determine the structure, you can digress to answer particular calls, you can't digress in a novel unless the author wants you to and that has a particular significance" (teacher interview).

"For example Ilsa: if the text was transcribed I would probably imagine her as younger and that sort of thing and in a novel, it would change your opinion on what Phelps was doing perhaps because it would seem more sleazy that he's going after her if she was younger because she was more middle-aged in L. A. Noire and if they hadn't actually described that in the novel then I would have thought she was a bit different" (student interview).

In the teacher response in the previous text, there appears to be, if not a contradiction, then at least some fertile ground for exploring the complexity of intertextual literacy and more or less fixed/permeable categories of reading. At the same time, the teacher is clear that games cannot be literature but is also able to articulate a series of intertextual and comparative judgements about the game, a novel and a play without the need for a separate critical discourse for each. Furthermore, the distinction between more active reading (of games) and less active reading but more apparently productive 'second-guessing' of author intention (in literature) reinforces the elements of subject English that most robustly deny learners a genuinely critical voice. There is no sense here that the teacher wittingly reinforces this and, indeed, muses on the interesting differences between the attractions of literature and gaming later in the discussion. But the absolute confidence in the clear difference between the two kinds of reading practice is 
at odds with the two student responses here. The comments on 'blatant intertexts' and the possibility of transcription into a novel articulate a prior acceptance of a more 'horizontal' textual field.

It is clear that student responses to questions about the 'status' of L. A. Noire as a novel were more consensual than their teachers - moving away from the simple affirmative to a shared dismantling of the premise of the question - a shared understanding of 'indiscipline', perhaps.

"Any changes, improvements or even 'transformations" are never consistent or straightforward and rarely turn out to be the inevitable and holistic improvements that some people would have us believe" (Selwyn, 2011, p. 176).

As Selwyn observes, changes to the relationships between humans, technology and learning are rarely linear, so our research here seeks to explore the complex of these potential transformations. The students who took part in our study seemed to be comfortable with this 'flattened' hierarchy between the novel, cinema and games. However, some of their teachers were reluctant, retreating to and rehearsing valueladen discourses of fidelity and verisimilitude. The 'tube map' example (Figure 2) is perhaps the best illustration of this tension, as it depicts the boundless heritage of noir and celebrates its connectivity; films, games, music and novels all coexist in a relativist 'bricolage', with no single utterance prioritised.

This could be partly explained by some teachers needing to 'perform' their 'front-region' (Goffman, 1990) of being an educator, whereas the students were more comfortable in their engagement outside the classroom. If this is merely a generational gap, and what we are seeing here is just the way in which young people use media today, then this will surely change. However, we suspect there are more complex and deep-rooted configurations of identity and habitus (Bourdieu, 1986) at work in English teaching, and these are far less likely to erode over time.
These findings are more complex than any 'Media 2.0' or digital natives/immigrants' polarising of schooled/ home cultures or ages (Berger and McDougall, 2011) can articulate. Many students drew on their acquired knowledge of literary theory in responding to some of the questions; Marxist and feminist theory was referred to a great deal, as were more contemporary works, such as Laura Mulvey's deconstruction of the 'male gaze' (2009). The students used 'paratexts' (Gray, 2010) to gain more contextual knowledge, whereas some teachers were more critical: they found fault with the narrative, one had a problem with what he perceived as anachronisms as problematic and another teacher was able to indicate how the text was derived from 'real' crimes and thus lacked originality, which may have been the inspiration for aspects of L. A. Noire's plot. Students were alert to the game's literary heritage, one describing it as an 'expandable book' and proved that literary theory can be used to analyse it, being - like a novel - relatively 'fixed' - as one student commented, the gameplay experience would be the same for 99 per cent of all players. This is untypical of videogames and so we cannot claim that all games can be studied in this way.

\section{Conclusions: (digital) transformations?}

Returning to our original research questions, it is clear for the students at least - that L. A. Noire does function as a (digitally transformed) novel, in relation to other texts, across a flattened hierarchy. It contains the utterance of literature, resonating in different media. The students seemed comfortable with this dynamic dialogism in which 'reading' is never centred on one text. Literary studies are generally concerned with 'closed off' or finished texts, and the perception that videogames are 'unfinished' was more of a problem for the teachers.

A 'pedagogy of the inexpert' is at work here as videogame literacy can be taught without being 'read' (played). Although students have much to offer teachers, and the

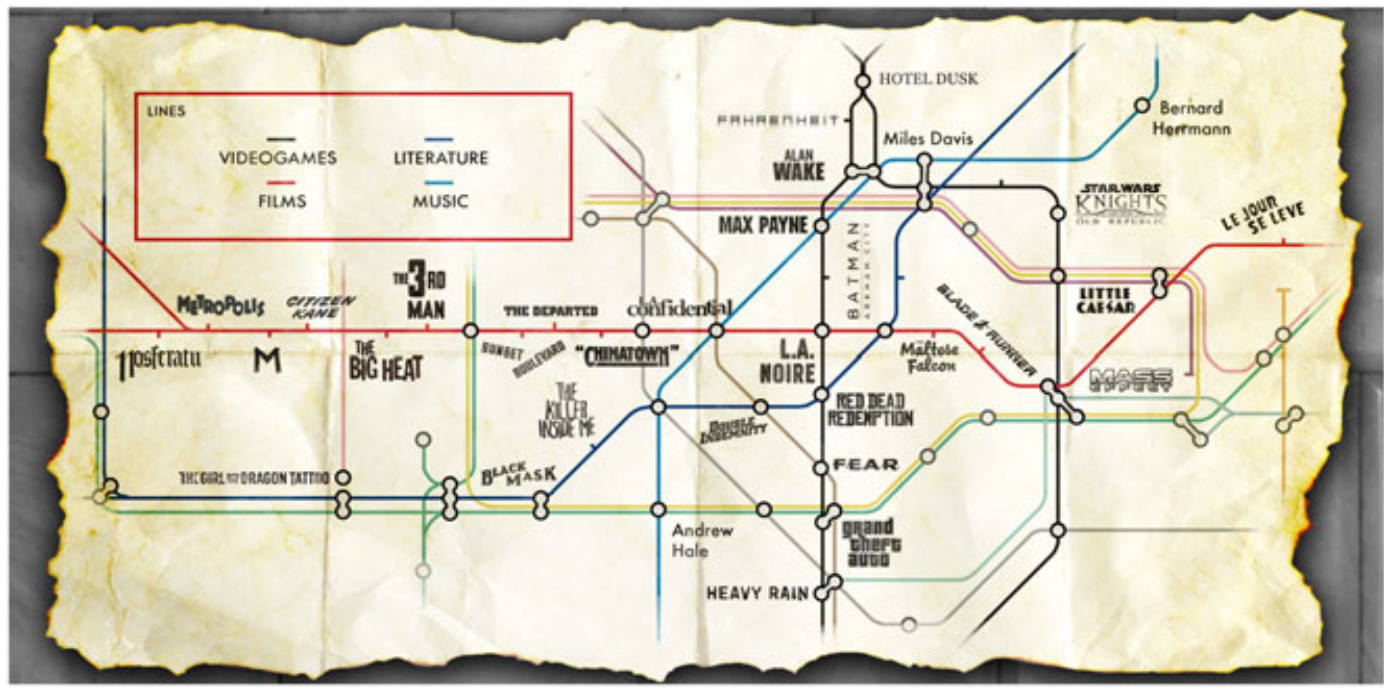

Figure 2: Bricolage 
dialogue between the two constituencies was always rich, the teachers' own knowledge and experience of literary theory can be unpacked by students when looking at games. The adoption of adaptation and appropriation as critical frameworks can liberate the curriculum from the 'delimiting' affect of its media-specific textual silos.

Thus, we conclude that the study of $L$. A. Noire explicitly reveals the limitations of subject English in the 'semipermeable' spaces between its teachers and students and in the complex ways in which each constituency comes to understand the ontology of being a reader.

\section{References}

ANDREWS, B. and MCDOUGALL, J. (2012) Curation pedagogy: further towards the inexpert. Medijkske Studije, 3.6, pp. 152-165.

APPERLEY, T. and WALSH, C. (2012) What digital games and literacy have in common: a heuristic for understanding pupils' gaming literacy. Literacy, 46.3, pp. 115-122.

ARTS AND HUMANITIES RESEARCH COUNCIL (2011) Digital transformations in the arts and humanities. Available at: http:/ / www.ahrc. ac.uk/Funding-Opportunities/Research-funding/Themes/DigitalTransformations/Pages/Digital-Transformations.aspx.

BAKHTIN, M. (1994). 'Speech genres', in P. Morris (Ed.) The Bakhtin Reader: Selected Writings of Bakhtin, Medvedev, Voloshinov. London: Arnold pp. 101-133.

BAZALGETTE, C. and BUCKINGHAM, D. (2012) Literacy, media and multimodality: a critical response. Literacy, Early View, DOI: 10.1111/j.1741-4369.2012.00666.x.

BENNETT, P., KENDALL, A. and MCDOUGALL, J. (2011) After the Media: Culture and Identity in the 21st Century. London: Routledge.

BERGER, R. (2012) 'Adaptation nation: medium specificity in the UK', in M. Bahloul and C. Graham (Eds.) Lights! Camera! Action and the Brain: The Use of Film in Education. Newcastle: Cambridge Scholars, pp. 33-60.

BERGER, R. and MCDOUGALL, J. (2011) Media studies 2.0: a retrospective. The Media Education Research Journal, 2.2, pp. 5-10.

BERNSTEIN, B. (1996) Pedagogy, Symbolic Control and Identity: Theory, Research, Critique. London: Taylor and Francis.

BOURDIEU, P. (1986) 'The forms of capital', in J. Richardson (Ed.) Handbook of Theory and Research for the Sociology of Education. New York: Greenwood Press, pp. 241-258.

COLLINS, J. (2010) Bring on the Books for Everybody: How Literary Culture Became Popular Culture. Durham, NC: Duke University Press.

COLVERT, A. (2012) 'What is the MFC? Making and shaping meaning in alternate reality games', in G. Merchant, J. Gillen, J. Marsh and J. Davies (Eds.) Virtual Literacies: Interactive Spaces for Children and Young People. London: Routledge Research in Education.

COULDRY, N. (2010) Why Voice Matters: Culture and Politics after Neoliberalism. London: Sage.

DAVIES, J. (2009) 'A space for play: crossing boundaries and learning online', in V. Carrington and M. Robinson (Eds.) Contentious Technologies: Digital Literacies, Social Learning and Classroom Practices. London: Sage.

DOWDALL, C. (2006) Dissonance between the digitally created words of school and home. Literacy, 40.3, pp. 153-163.

FAIRCLOUGH, N. (1995). Critical Discourse Analysis: The Critical Study of Language. London and New York: Routledge.

FOUCAULT, M. (1991) 'What is an author?', in P. Rabinow (Ed.) The Foucault Reader. London: Penguin Books, pp. 101-120.

GEE, J. (2003) What Video Games Have to Teach about Language and Literacy. New York: Palgrave Macmillan.

GEE, J. (2004) Situated Language and Learning. London: Routledge.

GEE, J. and HAYES, E. (2011). Learning and Language in the Digital Age. London: Routledge.

GODARD, J. (1965) Alphaville. France: Athos Films.

GOFFMAN, E. (1990) The Presentation of Self in Everyday Life. London: Penguin Books.
GRAHAM, L. (2008) Teachers are digikids too: the digital histories and digital lives of young teachers in English primary schools. Literacy, 42.1, pp. 10-18.

GRAY, J. (2010) Show Sold Separately: Promos, Spoilers and Other Media Paratexts. New York: New York University Press.

GRENFELL, M., BLOOME, D., HARDY, C., PAHL, K., ROSWELL, J., and STREET, B., (2012) Language, Ethnography and Education: Bridging New Literacy Studies and Bourdieu. London: Routledge.

GUTIEREZ, K. (2008) Developing a sociocritical literacy in the third space. Reading Research Quarterly, 43.2, pp. 148-164.

HANSON, C. (1997) L. A. Confidential. US: Warner Bros.

HOLLAND, D. and QUINN, N. (Eds.) (1998) Identity and Agency in Cultural Worlds. Cambridge, MA: Harvard University Press.

HOLQUIST, M. (2002) Dialogism. London: Routledge.

JENKINS, H. (2006) Game on! The future of literacy education in a participatory media culture. Threshold, Winter.

JUUL, J. (2005) Half-Real: Video Games between Real Rules and Fictional Worlds. Cambridge: MIT Press.

KENDALL, A. (2008) Playing and resisting: rethinking young people's reading cultures. Literacy, 42.3, pp. 123-130.

KENDALL, A. and MCDOUGALL, J. (2009) Just gaming: on being differently literate. Eludamos: Journal of Computer Game Culture, 3.2, pp. 245-260.

KENDALL, A. and MCDOUGALL, J. (2012) 'Telling stories out of school: young male gamers talk about literacy', in G. Merchant, J. Gillen, J. Marsh and J. Davies (Eds.) Virtual Literacies: Interactive Spaces for Children and Young People. London: Routledge Research in Education, pp. 89-102.

KRESS, G. (2010) Multimodality: A Social Semiotic Approach to Contemporary Communication. London: Routledge.

LYOTARD, J. and THEBAUD, J. (1985). Just Gaming. Minneapolis, MN: Minnesota University Press.

MARSH, J. (2007) New literacies and old pedagogies: recontextualising rules and practices. International Journal of Inclusive Education, 11.3, pp. 267-281.

MCDOUGALL, J. and O'BRIEN, W. (2008) Studying Videogames. Leighton Buzzard: Auteur.

MCDOUGALL, J. and PEIM, N. (2007) A Lacanian reading of the study of Big Brother in the English curriculum. Changing English, 14.3, pp. 299-312.

MERCHANT, G., GILLEN, J., MARSH, J. and DAVIES, J. (Eds.) (2012) Virtual Literacies: Interactive Spaces for Children and Young People. London: Routledge Research in Education.

MULVEY, L. (2009) Visual and Other Pleasures. London: Palgrave Macmillan.

PAHL, K. and ROSWELL, J. (2005) Literacy and Education: Understanding the New Literacy Studies in the Classroom. London: Paul Chapman.

POTTER, J. (2012) Digital Media and Learner Identity: The New Curatorship. New York: Palgrave MacMillan.

RANCIÈRE, J. (2009) The Emancipated Spectator. London: Verso.

RICHARDS, C. (2011) Young People, Popular Culture and Education. London: Continuum.

ROCKSTAR GAMES (2011) L. A. Noire: The Collected Stories. Glasgow: Rockstar.

SELWYN, N. (2011) Education and Technology; Key Issues and Debates. London: Continuum.

SELWYN, N. (2012) Ten suggestions for improving academic research in education and technology. Learning, Media and Technology, 37.3, pp. 213-219.

SUTHERLAND, J. (2007) How to Read a Novel: A User's Guide. London: Profile Books.

TODOROV, T. (1984) Mikhail Bakhtin: The Dialogical Principle. Manchester: Manchester University Press.

WELLES, O. (1958) A Touch of Evil. US: Universal International Pictures.

\section{CONTACT THE AUTHOR}

Julian McDougall, The Centre for Excellence in Media Practice, The Media School, Bournemouth University, Talbot Campus, Poole BH12 5BB, UK. e-mail: jmcdougall@bournemouth.ac.uk 